\title{
Diverging assessments of learning organizations during reform implementation
}

\begin{abstract}
Purpose - This study explores whether hierarchical position and organizational size affect perceptions of a learning organization during reform implementation.

Design/methodology/approach - An electronic survey was distributed in four Norwegian police districts at an early stage of reform implementation. One of the objectives of the reform was to develop the police towards being more knowledge-based and there had been specific calls for the police to become a learning organization. The respondents were 753 top managers, middle managers and employees.
\end{abstract}

Findings - Respondents rated their organizations lower than benchmark scores on supportive learning environment, learning processes and practices, and leadership that reinforces learning. The perceptions diverged across hierarchical levels: middle managers and top managers gave higher scores to the organization as a learning one than employees did. Respondents from large police districts gave higher scores to their organizational units as learning organizations than respondents from small police districts.

Research limitations/implications - The study captures perceptions of characteristics of a learning organization at one point in reform implementation, and further studies are needed to fully understand explanations of diverging views within an organization as to whether it can be characterized as a learning organization.

Practical implications - Actual differences in local learning practices or different assessments of learning practices within the organization should be considered when developing learning organizations.

Originality/value - The study contributes to our knowledge of learning organizations by showing diverging views within the same organization in a context of reform implementation.

Keywords: learning organization, learning practices, reform implementation, police services 


\section{Introduction}

The purpose of this paper is to explore whether hierarchical position and organizational size affect perceptions of a learning organization (LO) during reform implementation in four Norwegian police districts. This contributes to the LO literature in two ways. First, it builds on the importance of national and sector contexts (Örtenblad, 2013; 2017) and suggests public sector reform implementation as an additional dimension of context. In the Norwegian police reform, one of the objectives is to develop the police towards working in a more knowledgebased manner and a number of governmental reports implicitly and explicitly acknowledge the LO as an ideal (NOU 2009; NOU 2012; NOU 2013). Second, it explores diverging views within an organization about its learning characteristics. Previous research has identified challenges regarding LO in the police service (Filstad and Gottschalk, 2010; 2011; Wathne, 2012), but has relied on leaders' accounts. In a reform context, however, we might expect leaders and employees to have diverging perceptions. By including employees' accounts, we point to challenges of developing LOs, which may guide practitioners in their implementation work.

It is perhaps not surprising that organizational reforms adopt the idea of an LO as an ideal, implying expectations to organizations to develop learning practices, processes, structures and cultures. For example, studies of the police show a lack of a vision and strategy for organizational learning across organizational units (Filstad and Gottschalk, 2010; Wathne, 2012). In addition, police leaders' espoused values correspond only to a limited extent with the values that are assumed to be important to develop an LO (Filstad and Gottschalk, 2011). However, Wathne (2012) acknowledges that the police does have some well-functioning local learning practices but that there is scant knowledge sharing across organizational boundaries. If each organization is unique and must be given necessary flexibility to develop its own version of the learning organization (Pedler et al., 1991; Senge et al., 1994), we might expect diverging views of whether a large organization shares LO characteristics, because organizational members assess this from their particular position in the organization. An LO consists of local learning practices and practices to tie these together across organizational boundaries. This implies that local learning practices and learning processes may diverge considerably between organizational units in large organizations. The research reported in this paper answers a call for more pragmatic and divergent approaches to the LO by exploring how hierarchical position and organizational size affect the assessment of the learning practices and 
processes. This is especially important in reform implementation where a shared understanding of the status quo of the organization's learning potential could facilitate development work.

The paper is structured as follows. First, the literature on LOs is briefly reviewed and hypotheses are developed. Second, the research methods and data analysis are described. Finally, findings and contributions are discussed.

\section{Literature review}

The learning organization concept is based on the idea of an organization as a dynamic system that promotes continuous learning in response to various pressures (Grieves, 2008; Senge 1990), where individuals learn and transform themselves into a learning unit (Pedler et al., 1991). The concept still relies heavily on the originators' contributions; Pedler et al.'s (1991) learning company, Senge’s (1990) fifth discipline and Argyris and Schön's (1978) single and double-loop learning. The key point for learning organizations has traditionally been outcomes rather than mechanisms and processes of learning, and a unilateral focus on normative models for change, reconstruction and best practice of organizations (Elkjaer and Wahlgren, 2006; Laursen, 2006). The literature on the learning organization has been criticized for not sufficiently addressing how and why learning occurs (Senge and Kofman, 1995) but instead describing learning as more prescriptive than practical. First and foremost, a learning organization has been described as a set of actions that purport to ensure learning capabilities such as experimentation, continuous improvement, team work and group problem solving (Alegre and Chiva, 2008; Rebelo and Gomes, 2008). The learning organization concept, however, suffers from a lack of a clear definition that can be tested, and contested (Garvin, 2000; Grieves, 2008), and a lack of a clear description of the challenges of transforming an organization into a learning one (Bui and Baruch, 2010). However, the concept of the learning organization 'survives'. New contributions argue for the idea that each organization needs to create its own version of a learning organization (Örtenblad, 2004). The concept of a learning organization brings valuable insights to learning processes and a context for institutions to prove and reflect upon their incapacity (Örtenblad, 2011). Even though the literature shows differences concerning what constitutes an LO and whether LOs can be compared across cultures and sectors, there seems to be general agreement on local learning practices and learning processes being at the heart of the learning organization. Such practices and processes may vary considerably between organizational units in large organizations. This implies that 
there may be diverging views of the learning characteristics of large organizations and this may hamper attempts to improve learning.

Örtenblad (2013) suggests that four factors characterize the LO: workplace learning (continuous learning through practice, informal learning based in social practice, and knowledge sharing), organizational learning (learning based in organizational routines, shared understandings, organizational knowledge and organizational memory), climate for learning (leaders facilitating learning, workplace that initiates and stimulates learning), and structures for learning. Garvin et al. (2008) discussed three building blocks and developed the Learning Organization Survey (LOS), a diagnostic tool for organizations to rate the degree to which they share the characteristics of an LO: supportive learning environment, concrete learning processes and practices, and leadership that reinforces learning. The Dimensions of the Learning Organization Questionnaire (DLOQ) (Kim et al., 2015; Marsick and Watkins, 2003; Watkins and Dirani, 2013; Watkins and O’Neil, 2013; Yang et al., 2004) identifies seven factors characterizing an LO: it creates continuous learning opportunities, promotes inquiry and dialogue, encourages collaboration and team learning, creates systems to capture and share learning, empowers people toward a collective vision, connects the organization to its environment, and provides strategic leadership for learning.

Even though these examples illustrate different factor structures of the learning organization, there seem to be similarities between them. For example, supportive learning environment (Garvin et al., 2008) could be compared to climate for learning (Örtenblad, 2013), concrete learning processes and practices (Garvin et al., 2008) resemble workplace learning and organizational learning (Örtenblad, 2013), and leadership that reinforces learning is reflected in climate and structures for learning (Örtenblad, 2013). The study reported in this paper uses the three central building blocks for organizational learning and adaptability developed by Garvin and colleagues (2008, p. 110): 'a supportive learning environment, concrete learning processes and practices, and leadership behavior that provides reinforcement... Each block and its discrete subcomponents, though vital to the whole, are independent and can be measured separately.'

Senge's (1994) and Pedler and colleagues' (1991) work focused on businesses as LOs; however, in recent decades the concept has also led to considerable research and practical interest in several parts of the public sector. For example, the LOS (Garvin et al., 2008) has been adapted for use in health care (Singer et al., 2012) and schools (Higgins et al., 2012). The 
DLOQ has been adapted for non-profit organizations, higher education, government and the army (Watkins and O'Neil, 2013). The police in different parts of the world have been studied as learning organizations (Crank and Giacomazzi, 2009; Filstad and Gottschalk, 2010; 2011; 2013; Wathne, 2012). A meta-analysis of the DLOQ (Watkins and Dirani, 2013, p. 155) concluded that government respondents rated their organizations consistently below nongovernment respondents, but that 'the pattern of high and low dimensions is relatively consistent across government and nongovernment respondents'. Filstad and Gottschalk (2011; 2013) found a medium score on 'learning structures', and low score on 'learning at work', 'climate for learning', and 'organizational learning' among managers in the police. As the police is part of the public domain, we expect the respondents to rate their organization lower than benchmark scores for an LO:

Hypothesis 1: Respondents give their organization low ratings on the dimensions of learning organizations.

A meta-analysis of the DLOQ showed that non-managers rated five of seven dimensions significantly higher than managers did (Watkins and Dirani, 2013, p. 156): continuous learning, embedded systems, dialogue and inquiry, system connection and strategic leadership. This is interesting because we would expect that leaders and managers responsible for developing an LO would tend to be positive about the results of their efforts. However, these results also underscore that there may be large variations between organizational units, and that managers' scores could reflect a mean for the organization, while non-manager scores reflect their organizational unit. Studies of the preparations for the implementation of the Norwegian police reform, however, suggest that more managers than employees expressed positive views on the consequences of the reform because they were more involved in the implementation work (Renå et al., 2016) or because they gave their ratings according to espoused theory rather than their theory in use (Filstad and Gottschalk, 2011). Because elements of the learning organization are intertwined in the reform, it is likely that managers give their organization a higher rating for learning than employees.

Hypothesis 2: Middle managers give their organization a higher learning rating than employees in all three dimensions.

Hypothesis 3: Top managers give their organization a higher learning rating than middle managers in all three dimensions. 
We have not been able to find studies of LOs that explore whether there are different perceptions across organizational units of different size. However, organizational learning presupposes that information and knowledge can be shared easily in the organization and division of work, size and geographical dispersion could be structural barriers to learning (Lipshitz et al., 2007). This question is of particular relevance for the Norwegian police reform as the number of police districts was reduced from 27 to 12 . Naturally, this resulted in larger police districts, in terms of both the geographic region they cover and the number of employees.

Hypothesis 4: Large police districts score higher on all three dimensions of the learning organization than do small police districts.

\section{Research methods and data analysis}

An electronic survey was sent to top managers, middle managers and employees in four local police districts in January 2017. The survey was based on the LOS (Garvin et al., 2008) because it provided benchmark scores (Garvin et al., 2008, p. 14) that were necessary to test the hypotheses. The study was approved by the participating police districts, reported to and approved by the Norwegian privacy protection commission for research. Respondents were informed about the objectives of the study, that it was voluntary to participate, and that data provided could not be traced back to them personally or to their police district.

The 55 items developed by Garvin et al. (2008, pp. 112-113) were used. In line with research in particular contexts or organizations (Higgins et al., 2012; Singer et al., 2012) some items were modified to make the language specific to context. For example, market specific terms such as 'competitors' were changed to 'other police districts' as the police frequently compare results across police districts. The survey was translated into Norwegian and pretested to ensure that the respondents would understand the questions.

The building blocks 'supportive learning environment' and 'concrete learning processes and practices' were measured by 47 items that respondents were asked to rate on a seven-point scale. Instead of providing a description for each of the seven points as in the original survey, a scale where 1 indicated 'poor description' and 7 indicated 'perfect description' was chosen. 'Supportive learning environment' was measured by items reflecting psychological safety, appreciation of differences, openness to new ideas and time for reflection. Items reflecting experimentation, information collection, analysis, education and training, and information transfer measured 'concrete learning processes and practices'. Eight items that 
respondents were asked to state whether they agreed or disagreed with on a five-point scale measured the third building block 'leadership that reinforces learning'. The items described how managers facilitate learning and how they act as learning role models for example by inviting input from others, acknowledging their own limitations and asking probing questions.

A factor analysis (see Table 1) showed that the items in the translated survey load on two common factors that correspond with two of the components that the survey was intended to measure: 'supportive learning environment' and 'concrete learning processes and practices'. However, 'leadership that reinforces learning' loaded on the factor 'supportive learning environment'. Garvin et al. (2008) did not report factor analysis, Higgins et al. (2012) extracted one subscale from each of the building blocks and Singer et al. (2012) developed a short version of the survey with only 27 items. This makes it difficult to compare the results of our factor analysis with previous studies. However, Cronbach's alphas for the three factors are satisfactory and do not indicate problems with the Norwegian translation of the items supportive learning environment (0.838), concrete learning processes and practices (0.846), and leadership that reinforces learning (0.925).

Table 1. Factor analysis

\begin{tabular}{|l|c|c|c} 
& \multicolumn{4}{c}{ Rotated Component Matrix } \\
& & \\
& Component $=$ C \\
& 1 & 2 \\
\hline Factor 1 & Appreciation of differences (C1) & .901 & \\
\hline Openness to new ideas (C1) & .858 & \\
\hline Psychological Safety (C1) & .855 & \\
\hline Analysis (C2) & .650 & .445 \\
\hline Leadership that reinforces learning (C3) & .602 & .430 \\
\hline Time for reflection (C1) & .527 & \\
\hline Factor 2 Information collection (C2) & & .843 \\
\hline Information transfer (C2) & & .841 \\
\hline Experimentation (C2) & .311 & .718 \\
\hline Education and training (C2) & .502 & .626 \\
\hline
\end{tabular}

Extraction Method: Principal Component Analysis.

Rotation Method: Varimax with Kaiser Normalization.

a. Rotation converged in 3 iterations. 
Background questions about the respondent's position in the police district and the size of the police district where the respondent worked were included, allowing for the testing of hypotheses 2-4. Even though the reduction to 12 police districts was formally decided in 2016 , the practical mergers of the police districts were not finalized at the time of the study. Two large and two small police districts from the old structure of 27 police districts were invited to participate. The size of the police districts was defined with reference to the Norwegian context where a large police district had more than 500 employees and a small one had fewer than 500 .

Originally distributed to 2340 individuals in four police districts in January 2017, the survey yielded a response rate of $32.2 \%(\mathrm{~N}=753)$. While the response rate was not particularly high, the number of respondents was sufficient to allow careful statistical inferences about the population, given that we assumed the sample to be fairly representative, i.e. that nonresponse was random and not systematic. The survey was open for 30 days, and two reminders were sent to respondents. Considering that this period was a busy one regarding the reform implementation and that several police districts had experienced a large increase in research interest and invitations to surveys because of the reform, this response rate was satisfactory. The respondents included employees at all three levels of authority (29 top managers, 125 middle managers and 599 employees) and from small and large police districts, with a total of 216 and 535 respondents respectively.

\section{Results}

Hypothesis 1. Table 2 shows the median scores from the police survey. Overall, findings strengthened $\mathrm{H} 1$ that respondents give their organization a low rating on the dimensions of the LO. Within all the three building blocks, median scores from the survey were lower $(67.1,49.1$ and 70) than the corresponding benchmark scores (71, 74 and 76) (Garvin et al., 2008, p. 114). The police survey median scores were lower than the benchmark scores on seven of the nine underlying components of the building blocks, two notable exceptions being 'appreciation of differences' and 'time for reflection'. Regarding these seven components, five of the median scores from the police survey (openness to new ideas, experimentation, information gathering, education and training, information exchange) fell within the lowest quartile of the benchmark scores and two (psychological safety, analysis) fell within the second quartile.

Table 2. Median scores from the police survey. 


\begin{tabular}{|c|c|}
\hline & $\begin{array}{r}\text { SURVEY } \\
\text { MEDIAN } \\
\text { SCORES }\end{array}$ \\
\hline A supportive learning environment: & \\
- $\quad$ Psychological safety & 74.3 \\
- $\quad$ Appreciation of differences & 64.3 \\
- $\quad$ Openness to new ideas & 71.4 \\
- $\quad$ Time for reflection & 60.0 \\
Average score & 67.1 \\
\hline Learning processes and practices: & \\
- $\quad$ Experimentation & 42.9 \\
- $\quad$ Information gathering & 52.4 \\
- $\quad$ Analysis & 60.0 \\
- $\quad$ Education and training & 52.4 \\
- $\quad$ Information exchange & 42.9 \\
\hline Average score & 49.1 \\
\hline Leadership that reinforces learning & 70.0 \\
\hline Average score & \\
\hline
\end{tabular}

Hypothesis 2. This hypothesis was only partly supported by the data. As shown in Table 3, the survey findings indicated that middle managers on two of the three dimensions did tend to rate their organization as more of a learning organization than employees. Regarding 'leadership that reinforces learning', the opposite pattern was identified. However, t-tests showed that only one of the three differences in scores between the two groups, i.e. on the 'supportive learning' dimension, was statistically significant $(\mathrm{p}<0.01)$. When comparing the two groups' answers to the individual factors underlying the dimensions, t-tests demonstrated that 'time for reflection', 'experimentation' and 'information' stood out as there was no significant difference between employees and middle managers.

Table 3. Relationship between job level and size of police districts and scores on the three building blocks.

\begin{tabular}{|l|l|l|l|l|}
\hline & & $\begin{array}{c}\text { A supportive } \\
\text { learning } \\
\text { environment }\end{array}$ & $\begin{array}{c}\text { Learning } \\
\text { processes and } \\
\text { practices }\end{array}$ & $\begin{array}{c}\text { Leadership } \\
\text { that reinforces } \\
\text { learning }\end{array}$ \\
\hline Job level & Average scores & 77.8638 & 62.2762 & 76.8103 \\
\hline Operating unit manger &
\end{tabular}




\begin{tabular}{|l|l|c|c|c|}
\hline & $\mathrm{N}$ & 27 & 25 & 29 \\
\hline Middle manager with personnel & Average scores & 70.3205 & 50.8584 & 64.4612 \\
responsibility & $\mathrm{N}$ & 117 & 112 & 116 \\
\hline \multirow{2}{*}{$\begin{array}{l}\text { Employee without } \\
\text { managerial responsibility }\end{array}$} & Average scores & 65.0872 & 48.7396 & 67.2671 \\
& $\mathrm{~N}$ & 565 & 510 & 569 \\
\hline \multirow{2}{*}{ Total } & Average scores & 66.4374 & 49.6294 & 67.1989 \\
& $\mathrm{~N}$ & 709 & 647 & 714 \\
\hline \multirow{2}{*}{ Size of police district } & & & & \\
\hline Small (less than 500 employees) & Average scores & 64.9064 & 46.5561 & 63.4587 \\
\cline { 2 - 5 } & $\mathrm{N}$ & 206 & 186 & 206 \\
\hline Large (more than 500 employees) & Average scores & 66.9935 & 50.8617 & 68.6215 \\
\cline { 2 - 5 } & $\mathrm{N}$ & 501 & 461 & 506 \\
\hline Total & Average scores & 66.3854 & 49.6239 & 67.1278 \\
\cline { 2 - 5 } & $\mathrm{N}$ & 707 & 647 & 712 \\
\hline
\end{tabular}

Hypothesis 3. As expected, average scores in Table 3 show a clear difference between top managers and middle managers. On all three counts, the top managers gave their organization significantly higher scores than the middle managers, as demonstrated by t-tests $(p<0.01)$. Thus, H3 was strengthened. Among the individual factors, 'time for reflection' was found to be the only one where the difference in the two groups' ratings was not significant $(p>0.10)$.

Hypothesis 4. Average scores also indicated that respondents in large police districts rated their local organization on all three dimensions as more of a learning organization than their colleagues in smaller districts (see Table 3). On all three dimensions, the difference in scores was statistically significant $(\mathrm{p}<0.01)$. Consequently, $\mathrm{H} 4$ was strengthened by the data. Again, 'time for reflection' was the only underlying factor where the difference was not significant $(\mathrm{p}>0.10)$.

\section{Discussion}

The findings suggest some challenges regarding an LO, which confirms previous studies of police managers (Filstad and Gottschalk, 2010, 2011, 2013; Gottschalk et al., 2009; Wathne, 2012). Even though the LO is one of the important goals of the police reform, substantial challenges for learning and knowledge-based policing need to be addressed. When accounting 
for the whole organization and not only police leaders, as has been common in previous research, becoming an LO seems even more at a distance.

Our findings indicate major concerns regarding a supporting learning environment, concrete learning processes and leadership that reinforces learning. In fact, these factors mostly scored lower than the benchmark scores, with the only notable exceptions being appreciation of differences and time for reflection, both addressed as important variables for a supporting learning environment. What constitutes an LO is argued to be continuing learning in practices that represent structures, such as leadership and organization in teams, enabling these continuing learning processes for change and the creation of new knowledge (see original contributions from Argyris and Scön (1978); Pedler et al. (1991) and Senge et al. (1994)). However, organizations can prove and reflect upon their incapacity and capacity provided by learning structures, learning at work, climate for learning and organizational learning (Örtenblad, 2011). The factors of time for reflections and appreciation of differences found in this study are, however, not enough, but could represent a potential. Openness to new ideas and psychological safety, which scored quite low in our study, are needed for a supporting environment, as a climate for learning (Örtenblad, 2011). The low scores on information gathering and sharing provide serious challenges for organizational learning, where knowledge sharing bridges individual learning and organizational learning (Elkjaer and Wahlgren, 2006; Filstad, 2016). The acknowledgement of leaders as facilitators for learning and knowledge sharing and the importance of learning for the creation of a learning organization are not evident in our study, especially in the lower levels of policing.

It might be that the police is typical of the public sector. Watkins and Dirani (2013) find that managers in the public sector give their organizations a lower score on learning than managers in the private sector. However, their study does not account for diverging views within the organizations. The present study is an important contribution, adding knowledge by identifying diverging views on whether managers and employees consider their organization as an LO. This is in accordance with the understanding of a learning organization as built up of local learning practices and learning processes that may vary considerably within a large organization. The findings suggest that the higher up in the hierarchy the respondents were, the more positive they were in characterizing the organization's learning practices and processes. The present Norwegian reform context in the police conveys great expectations that leaders will develop an LO (NOU 2009, NOU 2012, NOU 2013). At the time of the study, the reform work and implementation was in an early stage with significant uncertainty for employees and 
managers regarding their future responsibilities and job roles. This may have influenced the respondents' responses because learning practices and learning processes may have had less focus, but on the other hand, their awareness of the need for learning due to the reform might also be higher. In addition, the lack of a clear vision and strategy on what constitutes a learning organization might explain the conflicting views we found among employees and managers on how good their organization is at learning. Managers may base their understanding on formal structures such as learning routines and reporting structures that may or may not operate as intended. Employees, on the other hand, may take as their baseline the actual learning practices that they engage in and their daily practice.

International research suggests that police mergers involve risks of competence loss at all levels (Holmberg, 2010; Mendell et al., 2017). Risk of competence loss is not measured in this study, but in light of previous research, the finding that large police districts are seen as providing more learning than small police districts is interesting. More knowledge is needed of whether and how an LO can mitigate the risks of competence loss in the context of mergers. In larger police districts, there are possibilities of greater specialization. While specialization answers the calls in the reform for more knowledge-based police services, it also demands coordination across specialities. Concrete learning processes and practices beyond organizational units could be established and encouraged to remedy the negative effects of specialization. In addition, local variation within the organization can be a source of learning because it can initiate discussions of good learning practices across organizational units.

\section{Conclusions and implications}

This study identifies a tendency that managers at higher levels are more positive to the idea of a learning organization than middle managers are, and that middle managers are more positive than employees are. The study also shows that respondents across hierarchical levels in large police districts give their organization a higher rating for learning than respondents in small police districts. The findings contribute to the literature on learning organizations by showing that there may be diverging views of the learning characteristics within large organizations. The definition of small and large police districts was tailored to the Norwegian context, and may not necessarily generalize to other countries. Therefore, we encourage more research to explore the issues of both hierarchy and organizational size and their impact on organizational learning. In our own data, regression analysis indicated that hierarchy overall had a stronger 
effect than size but the question remains to be answered by further research. The study's primary contribution is linked to the call for context in studies of LO (Örtenblad, 2017), suggesting that public sector reform implementation is a specific contextual dimension in addition to national culture, religion and sector affiliation, which have been studied in previous research. From a practitioner's perspective, it may be productive to ask how a top manager, middle manager or employee could contribute to developing a learning organization. This study shows that the respondents give the lowest scores on the building block concrete learning processes and learning practices. This gives leaders specific suggestions as to where learning efforts could be targeted. 


\section{References}

Alegre, J. and Chiva, R. (2008), "Assessing the impact of organizational learning capability on product innovation performance: an empirical test", Technovation, Vol. 28, pp. 315-326.

Bui, H. and Baruch, Y. (2010), "Creating learning organizations: a systems perspective", The Learning Organization, Vol. 17 No. 3, pp. 208-227.

Crank, J.P. and Giacomazzi, A. (2009), “A sheriff's office as a learning organization”, Police Quarterly, Vol. 12 No. 4, pp. 351-369.

Elkjær, B. and Wahlgren, B. (2006), "Organizational learning and workplace learning: Similarities and differences", in Antonacopoulou, E., Jarvis, P., Andersen, V., Elkjær, B. and Høyrup, S. (Eds.), Learning, Working and Living: Mapping the Terrain of Working Life Learning, Palgrave Macmillan, New York.

Filstad, C. (2016), Organisasjonslæring [Organizational learning], $2^{\text {nd }}$ ed., Bergen, Norway: Fagbokforlaget.

Filstad, C. and Gottschalk, P. (2014), "The police force: to be or not to be a learning organization?", in Örtenblad, A. (Ed.), Handbook of Research on the Learning Organization: Adaptation and Context, Edward Elgar, Cheltenham, UK.

Filstad, C. and Gottschalk, P. (2011), "Becoming a learning organization: The espoused values of police managers from two Norwegian districts", The Learning Organization, Vol. 18 No. 6, pp. 486-500.

Filstad, C. and Gottschalk, P. (2010), "Creating a learning organization in law enforcement: Maturity levels for police oversight agencies”, The Learning Organization, Vol. 17 No. 5, pp. 404-418.

Garvin, D.A. (2000), Learning in action: a guide to putting the learning organization to work, Harvard Business School Press, Boston, Massachusetts.

Garvin, D.A., Edmondson, A.C. and Gino, F. (2008), "Is yours a learning organization?" Harvard Business Review, Vol. 86 No. 3, pp. 109-116.

Gottschalk, P., Holgersson, S. and Karlsen, J.T. (2009), "How knowledge organizations work: the case of detectives", The Learning Organization, Vol. 16 No. 2, pp. 88-102.

Grieves, J. (2008), "Why we should abandon the idea of the learning organization", The Learning Organization, Vol. 15 No. 6, pp. 463-473.

Higgins, M., Ishimaru, A., Holcombe, R. and Fowler, A. (2012), "Examining Organizational Learning in Schools: The Role of Psychological Safety, Experimentation, and Leadership that Reinforces Learning", Journal of Educational Change, Vol. 13 No. 1, pp. 67-94.

Holmberg, L. (2010). From community policing to... Police reform in the Nordic countries. Paper presented at Nordic Criminology Conference, Copenhagen.

Kim, J., Egan, T. and Tolson, H. (2015), "Examining the dimensions of the learning organization questionnaire: A review and critique of research utilizing the DLOQ", Human Resources Development Review, Vol. 14 No. 1, pp. 91-112.

Laursen, E. (2006), "Knowledge, progression and the understanding of workplace learning", in Antonacopoulou, E., Jarvis, P., Andersen, V., Elkjær, B. and Høyrup, S. (Eds.), Learning, 
Working and Living: Mapping the Terrain of Working Life Learning, Palgrave Macmillan, New York.

Lipshitz, R., Friedman, V.J. and Popper, M. (2007), Demystifying organizational learning, Sage Publications, Thousand Oaks, California.

Marsick, V.J. and Watkins, K.E. (2003), "Demonstrating the value of an organization's learning culture: The dimensions of the learning organization questionnaire", Advances in Developing Human Resources, Vol. 5 No. 2, pp. 132-151.

Mendell, J., Fyfe, N.R. and den Heyer, G. (2017), "Does police size matter? A review of the evidence regarding restructuring police organizations", Police Practice and Research, Vol. 18 No. 1, pp. 3-14.

NOU (2009), Et ansvarlig politi. Apenhet, ansvarlighet og laering [A responsible police force. Openness, responsibility and learning], NOU 2009: 12, Evaluation report from a committee appointed by the Norwegian Ministry of Justice and the Police.

NOU (2012), Rapport fra 22. juli-kommisjonen [Report by the 22 July Commission], NOU 2012: 14, Appointed by royal resolution of 12 August 2011 to study and learn from the attacks on the government buildings and Utøya on 22 July 2011.

NOU (2013), Ett politi - rustet til å møte fremtidens utfordringer Politianalysen. [One police force: Equipped to meet the challenges of the future. Police analysis], NOU 2013: 9, Report by a committee appointed by the Norwegian Ministry of Justice and Public Security.

Örtenblad, A. (2017), “Taking 'The Learning Organization' into the future: introduction of and by the new editor", The Learning Organization, Vol 24 No 1, pp. 2-12.

Örtenblad, A. (2013), Handbook of research on the learning organization: Adaptation and context, Edward Elgar Publishing, Cheltenham, UK.

Örtenblad, A. (2011), Making sense of the learning organization: what is it and who needs it?, Yayasan Ilmuwan, Kuala Lumpur.

Pedler, M., Burgoyne, J. and Boydell, T. (1991), The learning company: A strategy for sustainable development, McGraw-Hill, London.

Rebelo, T.M. and Gomes, A.D. (2008), "Organizational learning and the learning organization: Reviewing evolution for prospecting the future", The Learning Organization, Vol. 15 No. 4, pp. 294-308.

Renå, H., Lægreid, P., Aars, J. and Glomseth, R. (2016), Ncerpolitireformen - politiansatte og lederes vurdering av dagens situasjon og forventninger til reformen [The Local Police Reform: Evaluation by police and leaders of the current situation and expectations for the reform]. Available at http:/www.uib.no/sites/w3.uib.no/files/attachments/rapportnaerpolitireformen_0.pdf (accessed 4 October 2017).

Singer, S.J., Moore, S.C., Meterko, M. and Williams, S. (2012), "Development of a short-form learning organization survey", Medical Care Research and Review, Vol. 69 No. 4, pp. 432459.

Senge, P.M. and Kofman, F. (1995), "Communities of commitment: the heart of learning organizations", in Chawla, S. and Renesch J. (Eds.), Learning Organizations: Developing Cultures for Tomorrow's Workplace, Productivity Press, Portland, Oregon, pp. 11-43. 
Senge, P., Ross, R., Smith, B., Roberts, C. and Kleiner, A. (1994), The fifth discipline fieldbook: strategies and tools for building a learning organization, Nicholas Brealey, London.

Senge, P. (1990), The fifth discipline: The art and practice of the learning organization, Currency Doubleday, New York.

Wathne, C.T. (2012), “The Norwegian Police Force: a learning organization?", Policing: An International Journal of Police Strategies \& Management, Vol. 35 No. 4, pp. 704-722.

Watkins, K.E. and O'Neil, J. (2013), "The dimensions of the learning organization questionnaire (the DLOQ): A nontechnical manual", Advances in Developing Human Resources, Vol. 15 No. 2, pp. 133-147.

Watkins, K.E. and Dirani, K.M. (2013), "A meta-analysis of the dimensions of a learning organization questionnaire: looking across cultures, ranks, and industries", Advances in Developing Human Resources, Vol. 15 No. 2, pp. 148-162.

Yang, B., Watkins, K.E. and Marsick, V.K. (2004), "The construct of the learning organization: Dimensions, measurement, and validation", Human Resource Development Quarterly, Vol 15 No. 1, pp. 31-55. 